\title{
Relationship between ambulatory arterial stiffness index and subclinical target organ damage in hypertensive patients
}

\author{
Ángel García-García ${ }^{1}$, Manuel A Gómez-Marcos ${ }^{1}$, José I Recio-Rodriguez ${ }^{1}$, Luis J González-Elena ${ }^{1}$, \\ Javier Parra-Sanchez ${ }^{1}, M^{\mathbf{a}}$ Fe Muñoz-Moreno ${ }^{1}$, Carmen Patino Alonso ${ }^{2}$, Francisco Gude ${ }^{3}$ \\ and Luis García-Ortiz ${ }^{1}$
}

Increased arterial stiffness has been shown to predict cardiovascular risk in hypertensive patients. Our objective was to evaluate the relationship between the ambulatory arterial stiffness index (AASI) and subclinical organ damage (SOD). The design was a cross-sectional study. Subjects included 554 hypertensive patients with and without drug treatment (mean age $57 \pm 12$ years, $60.6 \%$ men). The AASI was defined as 1 minus the regression slope of diastolic over systolic blood pressure (BP) readings obtained from 24-h recordings. Renal damage was evaluated on the basis of glomerular filtration rate (GFR) and microalbuminuria; vascular damage was measured by carotid intima-media thickness (IMT) and ankle/brachial index (ABI); and cardiac damage was evaluated on the basis of the Cornell voltage-duration product (VDP) and left ventricular mass index. The mean AASI was $0.38 \pm 0.07(0.39 \pm 0.07$ in treated patients and $0.37 \pm 0.06$ in nontreated subjects). The AASI showed a positive correlation with IMT $(r=0.417, P<0.001)$ and Cornell VDP $(r=0.188, P<0.001)$, and a negative correlation with GFR $(r=-0.205, P=0.001)$ and the ABI. The variables associated with the presence of SOD were AASI (odds ratio $(O R)=3.89)$ and smoking $(O R=1.55)$. The variables associated with IMT were smoking and waist circumference, whereas those associated with GFR were AASI, body mass index and waist circumference. In turn, smoking, total cholesterol and glycosylated hemoglobin A1c were associated with the ABI. Increased AASI implies a greater presence of SOD in primary hypertensive patients with or without BP-lowering drug treatment.

Hypertension Research (2011) 34, 180-186; doi:10.1038/hr.2010.195; published online 21 October 2010

Keywords: ambulatory blood pressure monitoring; carotid arteries; left ventricular hypertrophy; kidney diseases

\section{INTRODUCTION}

Arterial stiffness is currently regarded as an independent predictor of cardiovascular morbidity and mortality. ${ }^{1,2}$ The ambulatory arterial stiffness index (AASI) has been shown to be a better estimator of central arterial stiffness than other classical indicators, such as pulse pressure. ${ }^{3}$ Thus, although pulse pressure is a constant arterial stiffness index, AASI measures the dynamic relationship between systolic blood pressure (SBP) and diastolic blood pressure (DBP) over $24 \mathrm{~h}^{4}$ Similarly, AASI has been shown to be useful as a predictor of vascular mortality, ${ }^{3,5,6}$ particularly in reference to fatal and nonfatal stroke. ${ }^{7-9}$ In this context, AASI even outperforms the measurement of pulse wave velocity. ${ }^{10}$

According to the 2007 ESH-ESC (European Society of Hypertension/European Society of Cardiology) guidelines, ${ }^{11}$ the presence of subclinical organ damage (SOD) is of fundamental importance in determining the estimated cardiovascular risk with the proposed scale. Thus, subclinical renal damage, as evaluated on the basis of microalbuminuria and the glomerular filtration rate (GFR); cardiac damage, as measured by left ventricle hypertrophy (LVH); and vascular damage, which is evaluated on the basis of carotid intima-media thickness (IMT) and ankle/brachial index (ABI), are associated with an increased incidence of cardiovascular disease, ${ }^{12-15}$ and the presence of any such damage modifies the degree of vascular risk on the proposed risk scale. ${ }^{16,17}$

The correlation between IMT and central or core arterial stiffness has been explored in a number of studies. ${ }^{16,18,19}$ In this sense, the correlation has been shown to decrease with an increasing number of associated vascular risk factors. ${ }^{19}$ However, few studies have explored the relationship between AASI and SOD, ${ }^{20,21}$ and a review of the literature has yielded no studies analyzing this relationship on the basis of GFR, LVH, electrocardiogram (ECG) and the ABI as SOD indicators in hypertensive patients receiving drug treatment. This study evaluates the relationship between AASI and SOD at renal, cardiac and vascular levels by measuring these parameters with

${ }^{1}$ Primary Care Research Unit, La Alamedilla Health Centre, Salamanca, Spain; ${ }^{2}$ Statistics Department, University of Salamanca, Salamanca, Spain and ${ }^{3}$ Clinical Epidemiology Unit, Hospital Clínico Universitario de Santiago, Santiago de Compostela, Spain

Correspondence: Dr Á García-García, Primary Care Research Unit, La Alamedilla Health Centre, Avda. Comuneros, 27, Salamanca 37003, Spain.

E-mail: aglgarcia1@yahoo.es

Received 20 April 2010; revised 20 July 2010; accepted 28 July 2010; published online 21 October 2010 
different methods in hypertensive patients receiving drug treatment. This study also evaluates SOD in patients who are not receiving BP-lowering drug treatment.

\section{METHODS}

\section{Study design and population}

This was a cross-sectional study performed in a primary care setting. All patients included in the study were diagnosed with hypertension $<10$ years ago and visited their primary care clinics between January 2006 and June 2008. All participants agreed to take part in the study and were included by consecutive sampling.

The inclusion criteria were age 30-80 years, recently diagnosed or short/ medium-term clinical hypertension, no diagnosis of ischemic heart disease or cerebrovascular disease and complete assessment of the cardiovascular risk according to the 2007 ESH-ESC guidelines. ${ }^{11}$ Of the 618 patients recruited, 64 were excluded because of their diagnosis of ischemic heart disease or cerebrovascular disease; a total of 554 patients were ultimately included.

The sample size is sufficient to identify differences in AASI according to the associated SOD in the carotid artery, as measured by the IMT; in the heart, as measured by LVH with ECG tracing; and in the kidney, assuming an $\alpha$-risk of 0.05 and a $\beta$-risk of 0.20 in two-sided contrasting with a standard deviation (s.d.) of 0.10. In this context, we require 406 patients (ratio 1:6) for carotid SOD, 550 patients (ratio 1:9) for LVH with ECG and 550 patients (ratio 1:9) for renal SOD to detect AASI differences $\geqslant 0.04$. The protocol was approved by an independent ethics committee and all participants signed informed consent forms.

\section{BP measurement}

Clinical BP measurements were obtained by performing three measurements of SBP and DBP using a validated sphygmomanometer (Omron M7 model, Omron Health Care, Kyoto, Japan) following the recommendations of the $\mathrm{ESH} .{ }^{22}$ For the study, the mean of the last two measurements obtained by the nurse of the research unit was used. Pulse pressure was estimated with the mean values of the second and third measurements. We considered BP to be at target if clinical BP was lower than 140/90 $\mathrm{mm} \mathrm{Hg}$.

Ambulatory blood pressure monitoring was performed on a day of standard activity with a cuff adequate for the size of the patient's arm. A control system, the Spacelabs 90207 model (Spacelabs Healthcare, Issaquah, WA, USA), was used and validated according to the protocol of the British Hypertension Society. ${ }^{23}$ Of the total readings, $\geqslant 66 \%$ were considered valid. Furthermore, for the records to be valuable, at least 14 measurements were required during the daytime period or at least 7 during the night or rest period. The monitor was scheduled to obtain BP measurements every 20 min during the daytime and every $30 \mathrm{~min}$ during the rest period. The average and dispersion estimators of SBP and DBP were calculated for the total 24-h daytime and nighttime periods, respectively, and they were defined on the basis of the diary reported by the patient. Each patient completed a form specifying bedtime and wake-up time.

\section{SOD evaluation}

Cardiac assessment. The electrocardiographic examination was performed using a General Electric MAC 3.500 ECG System (General Electric, Niskayuna, NY, USA) that automatically measures the voltage and duration of waves and estimates the criteria of the Cornell voltage-duration product (Cornell VDP ${ }^{24}$ to assess the LVH. LVH is defined as the VDP $>2440 \mathrm{~mm}$ ms.

Echocardiographic examination was performed by two investigators specifically trained before the start of the study. A Sonosite Micromax device (Sonosite, Bothell, WA, USA) with a $2.5-3.5 \mathrm{MHz}$ linear transducer was used, with subjects lying down on their left sides. The measurements were performed according to the recommendations of the American Society of Echocardiography in mode M. ${ }^{25}$ Left ventricular mass was calculated using the Deveroux formula corrected for the body surface to estimate the left ventricular mass index. ${ }^{26}$ According to the European Hypertension Guidelines of 2007, LVH was defined as an left ventricular mass index $>125 \mathrm{~g} \mathrm{~m}^{-2}$ in men and $>110 \mathrm{~g} \mathrm{~m}^{-2}$ in women. ${ }^{11}$

Renal assessment. Kidney damage was assessed by measuring creatinine plasma concentration, the GFR was estimated by the Cockcroft-Gault ${ }^{27}$ and the MDRD (Modification of Diet in Renal Disease), ${ }^{28}$ and proteinuria was assessed by the albumin/creatinine ratio following the ESH 2007 criteria. ${ }^{11}$ SOD was defined as plasma creatinine of $1.3 \mathrm{mg}$ per $100 \mathrm{ml}$ or higher in men and $1.2 \mathrm{mg}$ per $100 \mathrm{ml}$ or higher in women, a GFR below $60 \mathrm{ml}$ per min or albumin/ creatinine ratio $>22 \mathrm{mg} \mathrm{g}^{-1}$ in men and $31 \mathrm{mgg}^{-1}$ in women. ${ }^{11}$

Assessment of carotid IMT. Carotid ultrasonography was performed by two investigators specifically trained to assess IMT before the start of the study. A Sonosite Micromax ultrasound device (Sonosite) paired with a $5-10 \mathrm{MHz}$ multifrequency high-resolution linear transducer with Sonocal software (Sonosite) was used for performing automatic measurements of IMT for optimizing reproducibility. Measurements were taken from the primitive carotid after the examination of a $10-\mathrm{mm}$ longitudinal section at $1 \mathrm{~cm}$ away from the bifurcation. We performed measurements of the anterior or proximal walls and of the posterior or distal walls in the lateral, anterior and posterior projections, following an axis perpendicular to the artery to discriminate two lines, one for the intima-blood interface and the other to the media-adventitious interface. A total of six measurements were obtained from the right carotid and another six of the left carotid, using average values (average IMT) and maximum values (maximum IMT) calculated by the software automatically. The measurements were obtained with the subject lying down, with the head extended and slightly turned in the opposite direction as the carotid being examined, following the recommendations of the Manheim Carotid IntimaMedia Thickness Consensus. ${ }^{29}$ The average IMT was considered abnormal if it was $>0.9 \mathrm{~mm}$ or if there were atherosclerotic plaques with a diameter $>1.5 \mathrm{~mm}$ or a focal increase of $0.5 \mathrm{~mm}$ or $50 \%$ of the adjacent IMT. ${ }^{11}$

Evaluation of peripheral artery disease. This parameter was evaluated using the $\mathrm{ABI}$ and was performed in the morning in patients who had not consumed coffee or tobacco for at least $8 \mathrm{~h}$ before measurement in an ambient temperature of $22-24^{\circ} \mathrm{C}$. With the feet uncovered and the patient in a supine position after $20 \mathrm{~min}$ of rest, the pressure in the lower extremities was measured using a portable Minidop Es-100Vx Doppler system (Hadeco, Arima, Miyamae-ku, Kawasaki, Japan). The probe was applied at the anterior or posterior tibial artery at an angle of $\sim 60^{\circ}$ relative to the direction of blood flow. The transducer's cuff was quickly inflated on each ankle to $\sim 30 \mathrm{~mm} \mathrm{Hg}$ above the systolic pressure, and the pressure was then allowed to descend (by $\sim 2 \mathrm{~mm} \mathrm{Hg}$ per second) until the first sound corresponding to the systolic pressure was heard. BP was also measured in both arms (measured twice at 3-5 min intervals). The ABI was calculated separately for each foot by dividing the higher of the two systolic pressures in the ankle by the higher of the two systolic pressures in the arm. SOD was considered if the ABI was lower than $0.9 .^{30}$

Estimations of AASI. AASI was defined as 1 minus the regression slope of DBP over SBP readings obtained from 24 -h recordings. ${ }^{3}$ The stiffer the arterial tree was, the closer the regression slope and AASI were to 0 and 1 , respectively. ${ }^{4,5}$

\section{Statistical analysis}

Continuous variables are expressed as mean \pm s.d., whereas qualitative variables are expressed on the basis of their frequency distribution. The difference in means between two-category qualitative variables was analyzed using Student's $t$-test for independent samples. Pearson's correlation coefficient was used to estimate the relationship between quantitative variables, and the $\chi^{2}$-test was applied to the association of qualitative variables.

The multivariate analysis involved a multiple linear regression model to analyze the variables; mean IMT, Cornell VDP, the Cockroft-Gault formula and the ABI were dependent variables. We included the independent variables AASI, age, sex and antihypertensive drugs in the first step using the 'enter' method. For the second step, we used a stepwise method and included as independent variables all those parameters that were statistically significant in the bivariate analysis, including total cholesterol ( $\mathrm{mg}$ per $100 \mathrm{ml}$ ), high-density lipoproteincholesterol (mg per $100 \mathrm{ml}$ ), low-density lipoprotein-cholesterol (mg per $100 \mathrm{ml}$ ), triglycerides (mg per $100 \mathrm{ml}$ ), diabetes mellitus, HbAlc (glycosylated hemoglobin Alc), smoking, heart rate, waist circumference, body mass index and years since the diagnosis of hypertension. 
In this analysis, we used dependent variables (namely mean IMT, Cornell VDP, the Cockroft-Gault formula and ABI), the same independent variables showed in Table 3 and adjusted variables using the enter method and statistically significant variables using the stepwise method.

Logistic regression analysis by the enter method was performed to evaluate the association between the different study parameters and SOD as the dependent variable ( 1 with SOD and 0 without SOD). Independent variables included sex, age, antihypertensive drug therapy, Ln (natural logarithm) AASI and smoking. An $\alpha$-risk of 0.05 was established as the limit of statistical significance. The SPSS/PC+ version 15.0 (SPSS, Chicago, IL, USA) statistical package was used throughout the study.

\section{RESULTS}

The general characteristics of the sample (336 men and 218 women) are shown in Table 1 . The mean AASI was $0.38 \pm 0.07$ and was greater in patients receiving drug treatment $(0.39 \pm 0.07)$ than in those without drug treatment $(0.37 \pm 0.06)(P<0.001)$. A greater proportion of vascular and cardiac SOD was also observed in patients receiving drug treatment (16.5 and $22.8 \%$, respectively) than in those without $(9.9$ and $14.0 \%$, respectively) $(P<0.05)$. We also found a higher proportion of vascular damage (16.2 vs. 9.7\%) in subjects with offtarget BP, but did not find heart or renal damage in these subjects.

\section{Table 1 General demographic and clinical characteristics, in hypertensive patients receiving or not antihypertensive treatment}

\begin{tabular}{|c|c|c|c|}
\hline Variables & Total (554) & Antihypertensive treatment (314) & Without antihypertensive treatment (240) \\
\hline Men $n(\%)$ & $336(60.6)$ & $193(61.5)$ & $143(59.6)$ \\
\hline Smoking & $126(22.7)$ & $66(21.1)$ & $60(25.0)$ \\
\hline $\mathrm{BMI}^{\dagger}$ & $28.27 \pm 4.15$ & $28.72 \pm 4.35$ & $27.68 \pm 3.80$ \\
\hline Waist circumference $(\mathrm{cm})^{*}$ & $97.91 \pm 11.37$ & $99.93 \pm 11.08$ & $95.25 \pm 11.23$ \\
\hline \multicolumn{4}{|l|}{ Office $B P(\mathrm{~mm} \mathrm{Hg})$} \\
\hline SBP & $139.93 \pm 18.32$ & $141.18 \pm 19.93$ & $138.30 \pm 15.85$ \\
\hline DBP & $87.58 \pm 10.60$ & $87.37 \pm 10.63$ & $87.86 \pm 10.56$ \\
\hline $\mathrm{HR}$ & $74.01 \pm 12.17$ & $73.41 \pm 12.16$ & $74.78 \pm 12.18$ \\
\hline \multicolumn{4}{|l|}{$A B P M 24 h(m m ~ H g)$} \\
\hline $\mathrm{SBP}^{\dagger}$ & $123.57 \pm 12.22$ & $122.50 \pm 12.84$ & $124.97 \pm 11.22$ \\
\hline $\mathrm{SBP}^{\dagger}$ & $127.43 \pm 12.41$ & $126.17 \pm 12,85$ & $129.08 \pm 11.64$ \\
\hline $\mathrm{DBP} *$ & $79.26 \pm 9.86$ & $77.23 \pm 9.87$ & $81.93 \pm 9.22$ \\
\hline $\mathrm{HR}^{\dagger}$ & $74.88 \pm 10.52$ & $73.67 \pm 10.65$ & $76.47 \pm 10.16$ \\
\hline \multicolumn{4}{|l|}{ Resting time ABPM ( $\mathrm{mm} \mathrm{Hg})$} \\
\hline $\mathrm{SBP}^{\dagger}$ & $113.37 \pm 14.38$ & $113.40 \pm 15.48$ & $113.34 \pm 12.83$ \\
\hline $\mathrm{DBP}^{\dagger}$ & $66.35 \pm 9.81$ & $65.28 \pm 9.91$ & $67.76 \pm 9.52$ \\
\hline $\mathrm{HR}^{\dagger}$ & $62.70 \pm 8.54$ & $62.64 \pm 8.74$ & $62.78 \pm 8.30$ \\
\hline AASI* & $0.38 \pm 0.07$ & $0.39 \pm 0.07$ & $0.37 \pm 0.06$ \\
\hline Creatinine $(\mathrm{mg} \text { per } 100 \mathrm{ml})^{\dagger}$ & $0.91 \pm 0.20$ & $0.93 \pm 0.22$ & $0.89 \pm 0.18$ \\
\hline Total cholesterol (mg per $100 \mathrm{ml}$ ) & $208.30 \pm 37.66$ & $206.05 \pm 38.68$ & $211.09 \pm 36.23$ \\
\hline HDL-c (mg per $100 \mathrm{ml}$ ) & $54.68 \pm 15.46$ & $53.67 \pm 14.67$ & $55.91 \pm 16.32$ \\
\hline Left $A B I$ & $1.09 \pm 0.17$ & $1.10 \pm 0,20$ & $1.07 \pm 0.13$ \\
\hline Right $A B I$ & $1.09 \pm 0.15$ & $1.10 \pm 0.17$ & $1.08 \pm 0.13$ \\
\hline \multicolumn{4}{|l|}{$S O D$} \\
\hline Renal & 69 (12.5) & $42(18.2)$ & $27(13.0)$ \\
\hline Vascular* & $54(9.7)$ & $35(16.5)$ & $19(9.9)$ \\
\hline Heart $\dagger$ & $91(16.4)$ & $60(22.8)$ & $31(14.0)$ \\
\hline
\end{tabular}

Abbreviations: AASI, ambulatory arterial stiffness index; $\mathrm{ABI}$, ankle/brachial index; $\mathrm{ABPM}$, ambulatory blood pressure monitoring; $\mathrm{BMI}$, body mass index; $\mathrm{BP}$, blood pressure; DBP, diastolic blood pressure; HbA1C, glycosylated hemoglobin Alc; HDL, high-density lipoprotein; HR, heart rate; IMT, intima-media thickness; LVMI, left ventricular mass index; MDRD, modification of diet in renal disease; SBP, systolic blood pressure; SOD, subclinical organ damage; VDP, voltage-duration product.

Data for qualitative variables are expressed as no. (\%) and quantitative variables, mean \pm s.d. The time course of HT is indicated in months. ${ }^{*} P \leqslant 0.001 ; \dagger P \leqslant 0.05$. 
The percentage of patients taking different families of antihypertensive drugs were as follows: $52.9 \%$ diuretics, $23.9 \% \quad \beta$-blockers, $22.8 \%$ angiotensin-converting enzyme inhibitors, $43 \%$ angiotensin receptor blockers, $15.9 \%$ calcium antagonists and $9 \%$ others. Figure 1 shows the percentage of patients taking a combination of drugs.

The univariate analysis showed AASI to be positively correlated with patient age $(r=0.495, P<0.001)$, IMT $(r=0.417, P<0.001)$, SBP $(r=0.349, \quad P=0.000)$, pulse pressure $(r=0.633, P<0.001)$, HbAlc $(r=0.245, P<0.001)$, Cornell VDP $(r=0.118, P<0.001)$, waist circumference $(r=0.130, P<0.001)$, body mass index $(r=0.135$, $P=0.001)$ and the time since the diagnosis of arterial hypertension $(r=0.260, P<0.001)$ (Table 2). Similarly, a negative correlation was

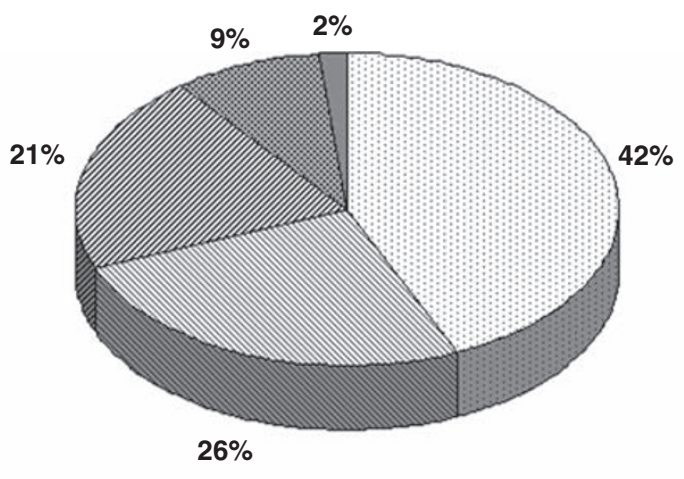

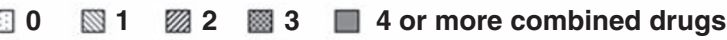

Figure 1 Drug treatment. Percentage of patients in relation to the number of antihypertensive drugs combined. observed with the Cockroft-Gault formula $(r=-0.205, P<0.001)$, DBP $(r=-0.261, P=0.001)$, heart rate $(r=-0.192, P=0.001)$ and the ABI $(r=-0.103, P=0.024)$.

Figure 2 shows that AASI was greater in patients with vascular SOD, in terms of both IMT $(0.424 \pm 0.060 v s .0 .367 \pm 0.062 ; P<0.001)$ and ABI $(0.393 \pm 0.065$ vs. $0.375 \pm 0.065 ; P<0.05)$. Similarly, AASI was greater in patients with cardiac SOD, as assessed by ECG tracing $(0.408 \pm 0.064$ vs. $0.347 \pm 0.080 ; P<0.05)$, although no differences were recorded in those subjects evaluated by echocardiography. With regard to renal SOD, we only found AASI to increase with the presence of lesions, as assessed by GFR (0.413 $\pm 0.712 v s$. $0.377 \pm 0.064 ; P=0.001$ ), but not when considering the albumin/ creatinine index. When we analyzed the relationship between AASI and SOD in patients with BP at target vs. those not at target, we found a similar behavior of AASI in all types of SOD except for LVH, as assessed by ECG, and for renal damage, as assessed by GFR. In these two cases, although AASI was greater in patients with SOD, we only found heart damage in patients with BP at target and only found statistically significant kidney damage in patients with off-target BP.

The multivariate analysis with multiple linear regression (Table 3), using IMT as a dependent variable in addition to control variables and AASI $(B=0.411 ; 95 \%$ confidence interval (95\% CI): $0.236-0.587$ ), included smoking ( $B=0.044$; 95\% CI: $0.020-0.068)$ and waist circumference in the equation $(B=0.001 ; 95 \%$ CI: $0.000-0.002)$. No variable was maintained with Cornell VDP, and AASI failed to reach statistical significance $(P=0.057)$. With the Cockroft-Gault formula as the dependent variable, the equation included AASI $(B=52.599 ; 95 \%$ CI: $22.297-82.901)$, body mass index $(B=1.772$; $95 \%$ CI: $1.011-$ $2.533)$ and waist circumference $(B=0.583$; 95\% CI: $0.280-0.886)$. With the $\mathrm{ABI}$, the equation maintained smoking $(B=-0.055$; 95\% CI: -0.105 to -0.006$)$, cholesterol $(B=-0.001 ; 95 \%$ CI: $-0.001-0.000)$ and HbAlc $(B=-0.024 ; 95 \%$ CI: -0.045 to -0.004$)$.

Table 2 Bivariate correlations of AASI with different variables and subclinical organ damage associated

\begin{tabular}{|c|c|c|c|c|c|c|}
\hline \multirow[b]{2}{*}{ Dependent variable } & \multicolumn{2}{|c|}{ All subjects } & \multicolumn{2}{|c|}{ With antihypertensive treatment } & \multicolumn{2}{|c|}{ Without antihypertensive treatment } \\
\hline & $A A S I$ & P-value & $A A S I$ & P-value & $A A S I$ & P-value \\
\hline Age & 0.495 & $<0.001$ & 0.514 & $<0.001$ & 0.414 & $<0.001$ \\
\hline Time evolution of the hypertension (years) & 0.260 & $<0.001$ & 0.256 & $<0.001$ & 0.049 & 0.638 \\
\hline Dominant arm office SBP & 0.349 & $<0.001$ & 0.441 & $<0.001$ & 0.142 & 0.028 \\
\hline Dominant arm office DBP & -0.261 & $<0.001$ & -0.164 & 0.004 & -0.419 & $<0.001$ \\
\hline Average HR & -0.192 & $<0.001$ & -0.164 & 0.004 & -0.221 & 0.001 \\
\hline Pulse pressure & 0.633 & $<0.001$ & 0.682 & $<0.001$ & 0.520 & $<0.001$ \\
\hline Waist circumference $(\mathrm{cm})$ & 0.130 & 0.002 & 0.108 & 0.056 & 0.082 & 0.207 \\
\hline BMI & 0.135 & 0.001 & 0.142 & 0.012 & 0.071 & 0.276 \\
\hline Total cholesterol (mg per $100 \mathrm{ml}$ ) & -0.107 & 0.016 & -0.158 & 0.008 & -0.002 & 0.974 \\
\hline HDL-c (mg per 100 ml) & 0.016 & 0.724 & 0.037 & 0.546 & 0.017 & 0.804 \\
\hline LDL-c (mg per $100 \mathrm{ml}$ ) & -0.115 & 0.011 & -0.174 & 0.004 & -0.003 & 0.963 \\
\hline Triglycerides (mg per 100 ml) & -0.014 & 0.752 & -0.018 & 0.758 & -0.013 & 0.846 \\
\hline $\mathrm{HbA1c}(\%)$ & 0.245 & $<0.001$ & 0.233 & $<0.001$ & 0.204 & 0.003 \\
\hline Average IMT & 0.417 & $<0.001$ & 0.369 & $<0.001$ & 0.461 & $<0.001$ \\
\hline Left $A B I$ & -0.103 & 0.024 & -0.101 & 0.104 & -0.140 & 0.038 \\
\hline Right ABI & -0.089 & 0.053 & -0.084 & 0.176 & -0.118 & 0.081 \\
\hline Cornell VDP & 0.188 & $<0.001$ & 0.244 & $<0.001$ & 0.071 & 0.295 \\
\hline LVMI $\left(\mathrm{g} \mathrm{m}^{2}\right)$ & 0.014 & 0.865 & 0.061 & 0.567 & -0.091 & 0.526 \\
\hline Cockroft-Gault & -0.205 & $<0.001$ & -0.158 & 0.008 & -0.216 & 0.001 \\
\hline MDRD & 0.008 & 0.854 & 0.081 & 0.173 & -0.042 & 0.529 \\
\hline Albumin/creatinine & 0.070 & 0.146 & 0.073 & 0.271 & 0.042 & 0.552 \\
\hline
\end{tabular}

Abbreviations: AASI, ambulatory arterial stiffness index; $\mathrm{ABI}$, ankle/brachial index; BMI, body mass index; BP, blood pressure; DBP, diastolic blood pressure; HbA1C, glycosylated hemoglobin A1c; HDL, high-density lipoprotein; HR, heart rate; IMT, intima-media thickness; LDL, Low-density lipoprotein; LVMI, left ventricular mass index; MDRD, modification of diet in renal disease; SBP, systolic blood pressure; damage; VDP, voltage-duration product. 

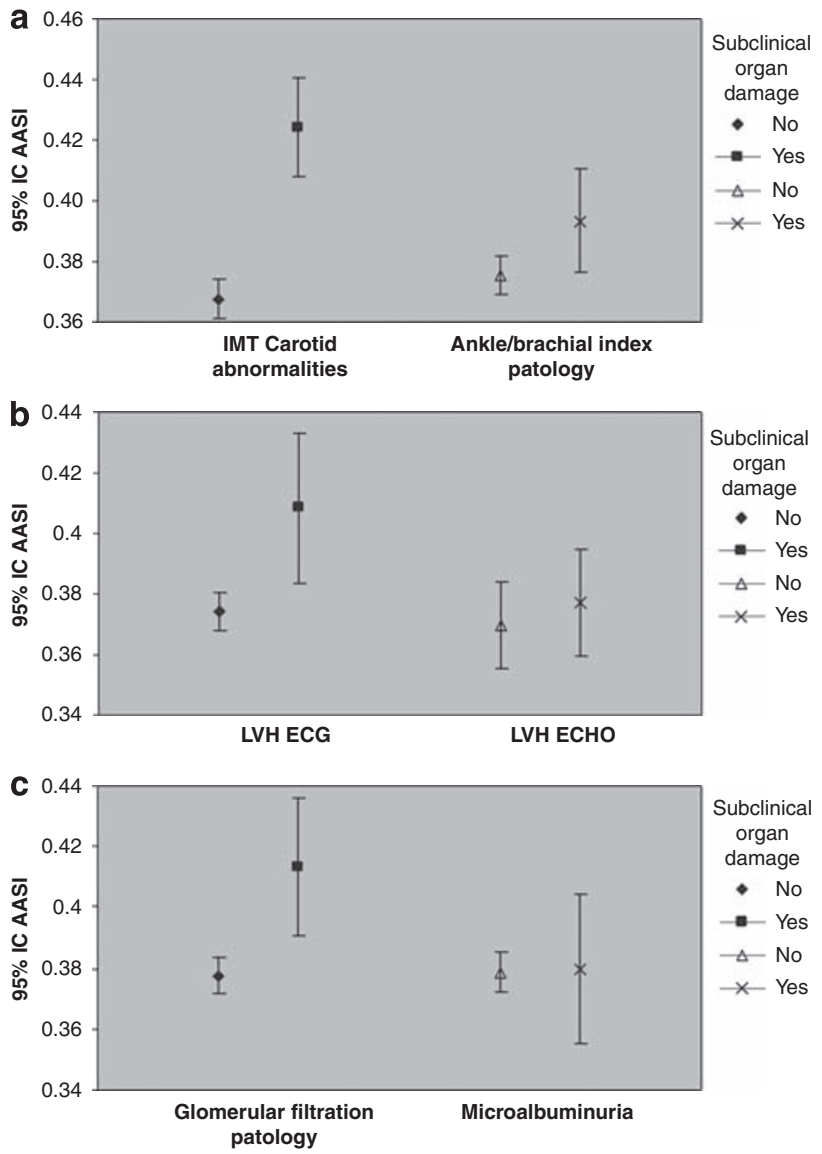

Figure 2 AASI and target organ damage. AASI was analyzed on the basis of the existence of subclinical organ damage (SOD) in all groups. (a) Vascular: carotid $(P<0.001)$ and ankle-brachial index $(A B I):(P=0.049)$, (b) left ventricular hypertrophy $(\mathrm{LVH})$ : electrocardiography $(P=0.001)$ and echocardiography $(P=519)$ and (c) kidney: glomerular filtration rate $(P=0.001)$ with the MDRD formula, Cockroft-Gault formula and microalbuminuria $(P=0.949)$.

AASI behavior was similar in subjects with BP at target and in those with off-target BP in terms of IMT and glomerular filtration, but not in terms of Cornell VDP ( $B=4101, P<0.05$ for those with BP at target and $B=457, P>0.05$ for those with off-target $\mathrm{BP})$ and left ABI $(B=-0.715, P<0.05$ for those with $\mathrm{BP}$ at target and $B=-0.075$, $P>0.05$ for subjects with off-target BP).

AASI (odds ratio $(\mathrm{OR})=3.890$ (95\% CI: 1.224-12.359)), smoking $(\mathrm{OR}=1.551$ (95\% CI: $1.013-$ to 2.373$))$ and age $(\mathrm{OR}=1.024$ (95\% CI: $1.007-1.042)$ ) were the only three variables to form part of the logistic regression model when using the presence of some types of SOD as the dependent variable (Table 4). However, AASI lost its predictive capacity in patients with uncontrolled BP (OR: 1.448, P>0.05). Therefore, smokers, older patients and patients with high AASI have an increased risk for target organ damage.

\section{DISCUSSION}

This study shows the relationship between AASI and SOD in hypertensive patients. This relationship is particularly striking in those patients who have been recently diagnosed as hypertensive and who are not on any medications but are instead treated with lifestyle modifications. In these patients, the increase in AASI is associated with vascular target organ damage, as measured by assessing the level of carotid and peripheral arterial disease. This finding suggests a loss of elasticity in the early stages of hypertension and reinforces the usefulness of AASI for the early detection of arterial stiffness and as a marker of vascular target organ damage. This study also demonstrates an association between AASI and renal SOD and reaffirms the importance of this index in the full assessment of hypertensive patients. In addition to the relationship found in untreated patients, we also observed a direct relationship between AASI and renal and vascular damage in hypertensive patients receiving drug therapy. However, in case of cardiac damage, this correlation was limited to patients with antihypertensive treatment. Similarly, AASI was an independent estimator of SOD. In this context, AASI even outperformed the classical vascular risk factors in patients both with and without antihypertensive drug treatment.

The relationship between AASI and certain target organ lesions in hypertensive patients was previously reported by Leoncini et al. ${ }^{20}$ in a series of 188 hypertensive patients who were not receiving drug treatment. The results of our study corroborate these findings and extend them to other target organs and to hypertensive patients who are receiving drug treatment and those with a longer course of high BP. Thus, the greater the AASI is, the greater the risk for SOD. The logistic regression analysis performed by Leoncini et al. ${ }^{20}$ yielded an OR for AASI of 1.886, considering damage to any target organ as a dependent variable. This value is lower than that obtained in our study with Ln AASI $(\mathrm{OR}=3.890)$. However, the loss of the predictive capacity of AASI for SOD in those patients with uncontrolled BP must be taken into account.

The association between AASI and other vascular lesions, such as the increase in carotid IMT, is a constant finding. However, the correlation coefficient obtained by Leoncini et al. ${ }^{20} \quad(r=0.196$, $P=0.015)$ is lower than that obtained in our series $(r=0.417$, $P<0.001$ ), possibly as a result of the longer course of hypertension in our patients. Similar to our study, Leoncini et al. ${ }^{20}$ observed greater AASI values in patients with carotid SOD (0.6) than in those without (0.5). With regard to peripheral arterial damage as assessed by the ABI, a negative correlation, which disappears in patients with hypertension of longer duration, has been found in nontreated individuals. Consequently, the relationship between AASI and the ankle/arm index is not clear.

The association between AASI and heart rate remains controversial. Thus, whereas Adiyaman et al. ${ }^{4}$ have reported a negative correlation similar to that found in our study, Li et al. ${ }^{3}$ recorded no relationship between these variables in their study of 348 patients who were not receiving antihypertensive treatment. However, although there are still a number of contradictory studies, heart rate and AASI are gaining importance as determinants of the dynamic measurement of arterial stiffness. ${ }^{4}$

The relationship between AASI and cardiac damage is not yet clear. In our series, we noted a positive correlation between AASI and Cornell VDP $(r=0.188, P<0.001)$, but not with the left ventricle mass index $(r=0.014, P=0.865)$. Our findings are in agreement with the observations of Leoncini et al. $(r=0.133, P=0.086)$ and Schillaci et al., ${ }^{21}$ who reported a statistically significant positive correlation between these parameters $(r=0.17, P<0.001)$. However, this correlation was not maintained in the corresponding multivariate analysis.

In terms of renal SOD, the results we obtained confirm the findings of Ratto et al. ${ }^{31}$ and Mulé et al., ${ }^{32}$ who reported a negative correlation between AASI and renal damage, as assessed by GFR $(r=-0.25$, $P=0.0018 ; r=-0.30, P<0.001$, respectively), and those of Hermans et al., ${ }^{33}$ who estimated renal damage on the basis of parameters, such as the MDRD formula and linked a lower GFR in intermediate stages of kidney disease to a greater increase in arterial stiffness. However, on evaluating renal damage by measuring urinary albumin excretion, we 
Table 3 Multivariate analysis

\begin{tabular}{|c|c|c|c|c|}
\hline Model & Variable & B & 95\% Confidence interval & P-value \\
\hline \multicolumn{5}{|c|}{ Dependent variable: average median IMT } \\
\hline & (Constant) & 0.167 & $0.056-0.278$ & 0.003 \\
\hline & Age* & 0.005 & $0.004-0.006$ & $<0.001$ \\
\hline & Antihypertensive drugs & 0.002 & -0.022 to 0.025 & 0.877 \\
\hline & AASI* & 0.411 & $0.236-0.587$ & $<0.001$ \\
\hline \multicolumn{5}{|c|}{ Dependent variable: Cornell VDP } \\
\hline & (Constant) & 803.090 & $90.727-1515.453$ & 0.027 \\
\hline & Sex* & -260.807 & -484.989 to -36.625 & 0.023 \\
\hline & Age & 3.644 & -7.781 to 15.070 & 0.531 \\
\hline & Antihypertensive drugs & 37.268 & -208.733 to 283.269 & 0.766 \\
\hline \multicolumn{5}{|c|}{ Dependent variable: Cockroft-Gault } \\
\hline & Age* & -1.635 & -1.827 to -1.443 & $<0.001$ \\
\hline & Antihypertensive drugs & -2.368 & -6.471 to 1.736 & 0.257 \\
\hline & AASI* & 52.599 & $22.297-82.901$ & 0.001 \\
\hline & Body mass index* & 1.772 & $1.011-2.533$ & $<0.001$ \\
\hline & Waist circumference $(\mathrm{cm})^{*}$ & 0.583 & $0.280-0.886$ & $<0.001$ \\
\hline \multicolumn{5}{|c|}{ Dependent variable: Left ABI } \\
\hline & (Constant) & 1.422 & $1.206-1.639$ & $<0.001$ \\
\hline & Sex & -0.023 & -0.068 to 0.021 & 0.301 \\
\hline & Age & 0.001 & -0.001 to 0.004 & 0.204 \\
\hline & Antihypertensive drugs & 0.023 & -0.026 to 0.072 & 0.355 \\
\hline & AASI & -0.358 & -0.719 to 0.003 & 0.052 \\
\hline
\end{tabular}

Abbreviations: AASI, ambulatory arterial stiffness index; ABI, ankle/brachial index; BMI, body mass index; HbA1C, glycosylated hemoglobin Alc; HDL, high-density lipoprotein; IMT, intima-media thickness; LDL, Low-density lipoprotein; VDP, voltage-duration product.

Related variables to different associated subclinical organ damage in hypertensive patients.

Dependent variables: average median IMT, VDP, estimated glomerular filtration rate Cockroft-Gault, ABI.

Independent variables: age, sex, antihypertensive treatment, AASI, smoking, waist circumference, total cholesterol, HDL-c (mg per $100 \mathrm{ml}$ ), LDL-c (mg per $100 \mathrm{ml}$ ), triglycerides, diabetes mellitus, $\mathrm{HbAlc}, \mathrm{BMI}$, heart rate and evolution years of the hypertension.

${ }^{*} P$ : statistically significant differences $(P<0.05)$. The enter method was used for the following variables: age, sex, AASI and antihypertensive treatment. Stepwise method was used for others independent variables.

Table 4 Logistic regression analysis considering as depending variable any target organ damage

\begin{tabular}{lcccc}
\hline Variable & $\mathrm{B}$ & $\mathrm{P}$ value & OR & OR (Cl 95\%) \\
\hline Sex (1: men/0: women) & 0.160 & 0.387 & 1.174 & $0.816-1.688$ \\
Age & 0.024 & 0.005 & 1.024 & $1.007-1.042$ \\
Antihypertensive drugs & 0.082 & 0.666 & 1.086 & $0.748-1.577$ \\
Ln AASI & 1.358 & 0.021 & 3.890 & $1.224-12.359$ \\
Smoking (1: smoker/ 0: nonsmoker) & 0.439 & 0.043 & 1.551 & $1.013-2.373$ \\
Constant & -0.705 & 0.440 & 0.494 &
\end{tabular}

Abbreviations: AASI, ambulatory arterial stiffness index; $\mathrm{Cl}$, confidence interval; Ln, natural logarithm; OR, odds ratio.

Logistic regression by the enter method. Dependent variables: any target organ damage (the heart, vascular or kidney). Independent variables: age, sex, antihypertensive drugs, Ln AASI and smoking.

observed no correlation with AASI. In contrast, such a correlation was reported by Leoncini et al. $;^{20}$ however, this correlation was reported after logarithmic transformation of the data.

The main limitation of our study is its cross-sectional design, which precludes longitudinal analysis between AASI and SOD. Another limitation is the selection of the study population; sampling was performed consecutively with pragmatic and broad inclusion criteria. Therefore, the study population includes hypertensive patients with a recent diagnosis or a short course of hypertension, some subjects with diabetes and hyperlipidemia, and many patients who were receiving drug therapy. These circumstances may modify BP levels and, therefore, may limit the validity of some results. However, the results did not change after controlling for these variables in the multivariate analysis. Consequently, the heterogeneity of the sample could lead to some limitations when interpreting the results, although the sample is quite similar to the distribution of the actual population of shortcourse hypertensive patients with some risk factors and no previous cardiovascular disease.

In conclusion, increased AASI implies an increased presence of associated vascular, cardiac and renal SOD in primary hypertensive patients with or without BP-lowering drug treatment. Thus, AASI could offer added predictive value to the evaluation of vascular risk. Finally, we consider that further prospective studies of AASI in the general population are required to assess the theory of a possible 
increase in arterial stiffness in the early stages of arterial hypertension and before the development of SOD. The results of this study confirm the potential importance of AASI in the early detection of target organ damage in hypertensive patients, regardless of the duration of high BP and the use or absence of antihypertensive drug therapy. In this sense, AASI could be used to more efficiently evaluate cardiovascular risk.

\section{CONFLICT OF INTEREST}

The authors declare no conflict of interest.

\section{ACKNOWLEDGEMENTS}

This project was supported by the Regional Health Management of Castilla y León (GRS275 /B/08) and by the Carlos III Health Institute (ISCIII-RETICS RD06/0018).

1 Hayashi T, Nakayama Y, Tsumura K, Yoshimaru K, Ueda H. Reflection in the arterial system and the risk of coronary heart disease. Am J Hypertens 2002; 15: 405-409.

2 Willum-Hansen T, Staessen JA, Torp-Pedersen C, Rasmussen S, Thijs L, Ibsen H, Jeppesen J. Prognostic value of aortic pulse wave velocity as index of arterial stiffness in the general population. Circulation 2006; 113: 664-670.

3 Li Y, Wang JG, Dolan E, Gao PJ, Guo HF, Nawrot T, Stanton AV, Zhu DL, O'Brien E, Staessen JA. Ambulatory arterial stiffness lindex derived from $24-\mathrm{H}$ ambulatory blood pressure monitoring. Hypertension 2006; 47: 359-364.

4 Adiyaman A, Dechering DG, Boggia J, Li Y, Hansen TW, Kikuya M, Björklund-Bodegård K, Richart T, Thijs L, Torp-Pedersen C, Ohkubo T, Dolan E, Imai Y, Sandoya E, Ibsen H, Wang J, Lind L, O'Brien E, Thien T, Staessen JA, International Database on Ambulatory Blood Pressure Monitoring in Relation to Cardiovascular Outcomes Investigators. Determinants of the ambulatory arterial stiffness index in 7604 subjects from 6 populations. Hypertension 2008; 52: 1038-1044.

5 Dolan E, Thijs L, Li Y, Atkins N, McCormack P, McClory S, O’Brien E, Staessen JA, Stanton AV. Ambulatory arterial stiffness index as a predictor of cardiovascular mortality in the Dublin Outcome Study. Hypertension 2006; 47: 365-370.

6 Gavish B, Ben-Dov IZ, Kark JD, Mekler J, Bursztyn M. The association of a simple blood pressure-independent parameter derived from ambulatory blood pressure variability with short-term mortality. Hypertens Res 2009; 32: 488-495.

7 Kikuya M, Staessen JA, Ohkubo T, Thijs L, Metoki H, Asayama K, Obara T, Inoue R, Li Y, Dolan E, Hoshi H, Hashimoto J, Totsune K, Satoh H, Wang JG, O'Brien E, Imai Y. Ambulatory arterial stiffness index and $24-\mathrm{H}$ ambulatory pulse pressure as predictors of mortality in Ohasama, Japan. Stroke 2007; 38: 1161-1166.

8 Muxfeldt ES, Fiszman R, Castelpoggi CH, Salles GF. Ambulatory arterial stiffness index or pulse pressure: which correlates better with arterial stiffness in resistant hypertension? Hypertens Res 2008; 31: 607-613.

9 Hansen TW, Staessen JA, Torp-Pedersen C, Rasmussen S, Li Y, Dolan E, Thijs L, Wang JG, O'Brien E, Ibsen H, Jeppesen J. Ambulatory arterial stiffness index predicts stroke in a general population. J Hypertens 2006; 24: 2247-2253.

10 Hansen TW, Li Y, Staessen JA, Jeppesen J, Rasmussen S, Wang JG, Thijs L, Ibsen H, Safar ME, Torp-Pedersen C. Independent prognostic value of the ambulatory arterial stiffness index and aortic pulse wave velocity in a general population. $J$ Hum Hypertens 2008; 22: 214-216.

11 Mancia G, De Backer G, Dominiczak A, Cifkova R, Fagard R, Germano G, Grassi G, Heagerty AM, Kjeldsen SE, Laurent S, Narkiewicz K, Ruilope L, Rynkiewicz A, Schmieder RE, Boudier HA, Zanchetti A, Vahanian A, Camm J, De Caterina R, Dean V, Dickstein K, Filippatos G, Funck-Brentano C, Hellemans I, Kristensen SD, McGregor K, Sechtem U, Silber S, Tendera M, Widimsky P, Zamorano JL, Erdine S, Kiowski W, Agabiti-Rosei E, Ambrosioni E, Lindholm LH, Viigimaa M, Adamopoulos S, AgabitiRosei E, Ambrosioni E, Bertomeu V, Clement D, Erdine S, Farsang C, Gaita D, Lip G, Mallion JM, Manolis AJ, Nilsson PM, O'Brien E, Ponikowski P, Redon J, Ruschitzka F, Tamargo J, van Zwieten P, Waeber B, Williams B, Management of Arterial Hypertension of the European Society of Hypertension; European Society of Cardiology. 2007 Guidelines for the management of arterial hypertension. The Task Force for the management of arterial hypertension of the European Society of Hypertension (ESH) and of the European Society of Cardiology (ESC). J Hypertens 2007; 25: 1105-1187.

12 Levy D, Garrison RJ, Savage DD, Kannel WB, Castelli WP. Prognostic implications of echocardiographically determined left ventricular mass in the Framingham Heart Study. N Engl J Med 1990; 322: 1561-1566.

13 Levy D, Salomon M, D’Agostino RB, Belanger AJ, Kannel WB. Prognostic implications of baseline electrocardiographic features and their serial changes in subjects with left ventricular hypertrophy. Circulation 1994; 90: 1786-1793.

14 Okin PM, Devereux RB, Jern S, Kjeldsen SE, Julius S, Nieminen MS, Snapinn S, Harris KE, Aurup P, Edelman JM, Wedel H, Lindholm LH, Dahlöf B. Regression of electrocardiographic left ventricular hypertrophy during antihypertensive treatment and the prediction of major cardiovascular events. JAMA 2004; 292: 2343-2349.

15 Sarnak MJ, Levey AS, Schoolwerth AC, Coresh J, Culleton B, Hamm LL, McCullough PA, Kasiske BL, Kelepouris E, Klag MJ, Parfrey P, Pfeffer M, Raij L, Spinosa DJ, Wilson PW. Kidney disease as a risk factor for development of cardiovascular disease: a statement from the American Heart Association Councils on Kidney in Cardiovascular
Disease, High Blood Pressure Research, Clinical Cardiology, and Epidemiology and Prevention. Circulation 2003; 108: 2154-2169.

16 O'Leary DH, Polak JF, Kronmal RA, Manolio TA, Burke GL, Wolfson Jr SK. Carotid-artery intima and media thickness as a risk factor for myocardial infarction and stroke in older adults. Cardiovascular Health Study Collaborative Research Group. N Engl J Med 1999; 340: 14-22.

17 Satoh N, Shimatsu A, Kato Y, Araki R, Koyama K, Okajima T, Tanabe M, Ooishi M, Kotani K, Ogawa Y. Evaluation of the cardio-ankle vascular index, a new indicator of arterial stiffness independent of blood pressure, in obesity and metabolic syndrome. Hypertens Res 2008; 31: 1921-1930.

18 Mattace-Raso FU, van der Cammen TJ, Hofman A, van Popele NM, Bos ML, Schalekamp MA, Asmar R, Reneman RS, Hoeks AP, Breteler MM, Witteman JC. Arterial stiffness and risk of coronary heart disease and stroke: the Rotterdam Study. Circulation 2006; 113: 657-663.

19 Paini A, Boutouyrie P, Calvet D, Tropeano AI, Laloux B, Laurent S. Carotid and aortic stiffness. Determinants of discrepancies. Hypertension 2006; 47: 371-376.

20 Leoncini G, Ratto E, Viazzi F, Vaccaro V, Parodi A, Falqui V, Conti N, Tomolillo C, Deferrari G, Pontremoli R. Increased ambulatory arterial stiffness index is associated with target organ damage in primary hypertension. Hypertension 2006; 48: 397-403.

21 Schillaci G, Parati G, Pirro M, Pucci G, Mannarino MR, Sperandini L, Mannarino E. Ambulatory arterial stiffness index is not a specific marker of reduced arterial compliance. Hypertension 2007; 49: 986-991.

22 O'Brien E, Asmar R, Beilin L, Imai Y, Mancia G, Mengden T, Myers M, Padfield P, Palatini P, Parati G, Pickering T, Redon J, Staessen J, Stergiou G, Verdecchia P, European Society of Hypertension Working Group on Blood Pressure Monitoring. Practice guidelines of the European Society of Hypertension for clinic, ambulatory and self blood pressure measurement. J Hypertens 2005; 23: 697-701.

23 O'Brien E, Petrie J, Littler W, de Swiet M, Padfield PL, O'Malley K, Jamieson M, Altman D, Bland M, Atkins N. The British Hypertension Society protocol for the evaluation of automated and semi-automated blood pressure measuring devices with special reference to ambulatory systems. J Hypertens 1990; 8: 607-619.

24 Okin PM, Roman MJ, Devereux RB, Kligfield P. Electrocardiographic identification of increased left ventricular mass by simple voltage-duration products. J Am Coll Cardiol 1995; 25: 417-423.

25 Schiller NB, Shah PM, Crawford M, DeMaria A, Devereux R, Feigenbaum H, Gutgesell H, Reichek N, Sahn D, Schnittger I, Silverman NH, Tajik AJ. Recommendations for quantitation of the left ventricle by two-dimensional echocardiography. American Society of Echocardiography Committee on Standards, Subcommittee on Quantitation of Two-dimensional Echocardiograms. J Am Soc Echocardiogr 1989; 2: 358-367.

26 Devereux RB, Alonso DR, Lutas EM, Gottlieb GJ, Campo E, Sachs I, Reichek N. Echocardiographic assessment of left ventricular hypertrophy: comparison to necropsy findings. Am J Cardiol 1986; 57: 450-458.

27 Cockcroft DW, Gault MH. Prediction of creatinine clearance from serum creatinine. Nephron 1976; 16: 31-41.

28 Levey AS, Bosch JP, Lewis JB, Greene T, Rogers N, Roth D. A more accurate method to estimate glomerular filtration rate from serum creatinine: a new prediction equation. Modification of Diet in Renal Disease Study Group. Ann Intern Med 1999; 130: 461-470.

29 Touboul PJ, Hennerici MG, Meairs S, Adams H, Amarenco P, Bornstein N, Csiba L, Desvarieux M, Ebrahim S, Fatar M, Hernandez Hernandez R, Jaff M, Kownator S, Prati P, Rundek T, Sitzer M, Schminke U, Tardif JC, Taylor A, Vicaut E, Woo KS, Zannad F, Zureik M. Mannheim carotid intima-media thickness consensus (2004-2006). An update on behalf of the Advisory Board of the 3rd and 4th Watching the Risk Symposium, 13th and 15th European Stroke Conferences, Mannheim, Germany, 2004, and Brussels, Belgium, 2006. Cerebrovasc Dis 2007; 23: 75-80.

30 Hirsch AT, Haskal ZJ, Hertzer NR, Bakal CW, Creager MA, Halperin JL, Hiratzka LF, Murphy WR, Olin JW, Puschett JB, Rosenfield KA, Sacks D, Stanley JC, Taylor Jr LM, White CJ, White J, White RA, Antman EM, Smith Jr SC, Adams CD, Anderson JL, Faxon DP, Fuster V, Gibbons RJ, Hunt SA, Jacobs AK, Nishimura R, Ornato JP, Page RL, Riegel B, American Association for Vascular Surgery; Society for Vascular Surgery; Society for Cardiovascular Angiography and Interventions; Society for Vascular Medicine and Biology; Society of Interventional Radiology; ACC/AHA Task Force on Practice Guidelines Writing Committee to Develop Guidelines for the Management of Patients With Peripheral Arterial Disease; American Association of Cardiovascular and Pulmonary Rehabilitation; National Heart, Lung, Blood Institute; Society for Vascular Nursing; TransAtlantic Inter-Society Consensus; Vascular Disease Foundation. ACC/AHA 2005 Practice Guidelines for the management of patients with peripheral arterial disease (lower extremity, renal, mesenteric, and abdominal aortic): a collaborative report from the American Association for Vascular Surgery/Society for Vascular Surgery, Society for Cardiovascular Angiography and Interventions, Society for Vascular Medicine and Biology, Society of Interventional Radiology, and the ACC/AHA Task Force on Practice Guidelines. Circulation 2006; 113: e463-e654

31 Ratto E, Leoncini G, Viazzi F, Vaccaro V, Falqui V, Parodi A, Conti N, Tomolillo C, Deferrari G, Pontremoli R. Ambulatory arterial stiffness index and renal abnormalities in primary hypertension. J Hypertens 2006; 24: 2033-2038.

32 Mulè G, Cottone S, Cusimano P, Incalcaterra F, Giandalia M, Costanzo M, Nardi E, Palermo A, Geraci C, Costa R, Cerasola G. Inverse relationship between ambulatory arterial stiffness index and glomerular filtration rate in arterial hypertension. Am J Hypertens 2008; 21: 35-40.

33 Hermans MM, Henry R, Dekker JM, Kooman JP, Kostense PJ, Nijpels G, Heine RJ, Stehouwer $\mathrm{CD}$. Estimated glomerular filtration rate and urinary albumin excretion are independently associated with greater arterial stiffness: the Hoorn Study. J Am Soc Nephrol 2007; 18: 1942-1952. 